\title{
Erratum: Analytical Studies on the Synchronization of a Network of Linearly-Coupled Simple Chaotic Systems
}

\author{
[J. Korean Phys. Soc. 72, 1121 (2018)] \\ DOI: $10.3938 / \mathrm{jkps} .72 .1121$ \\ G. Sivaganesh \\ Department of Physics, Alagappa Chettiar College of Engineering 63 Technology, Karaikudi, Tamilnadu-630 004, India \\ A. Arulgnanam* \\ Department of Physics, St. John's College, Palayamkottai, Tamilnadu-627 002, India \\ A. N. Seethalakshmi and S. Selvaraj \\ Department of Physics, The M.D.T Hindu College, Tirunelveli, Tamilnadu-627 010, India
}

DOI: $10.3938 / \mathrm{jkps} .73 .399$

The affiliation of A. Arulgnanam is incorrect. It should be corrected as "Department of Physics, St. John's College, Palayamkottai - 627 002, Tamilnadu, India and Affiliated to Manonmaniam Sundaranar University, Abishekapatti, Tirunelveli - 627 012, Tamilnadu, India".

The affiliation of A. N. Seethalakshmi and S. Selvaraj is incorrect. It should be corrected as "Department of Physics, The M.D.T Hindu College, Tirunelveli - 627 010, Tamilnadu, India and Affiliated to Manonmaniam Sundaranar University, Abishekapatti, Tirunelveli - 627 012, Tamilnadu, India".

*E-mail: gospelin@gmail.com 